\title{
Six-fold increased risk of hip fracture in older Australians ( $\geq 60$ years) with dementia
}

\author{
Alexander A. Fisher • Michael W. Davis • \\ Wichat Srikusalanukul • Marc M. Budge
}

Received: 10 March 2006 / Accepted: 13 June 2006 / Published online: 5 August 2006

(C) International Osteoporosis Foundation and National Osteoporosis Foundation 2006

\begin{abstract}
Introduction The objectives were: (1) to estimate the prevalence of dementia in older people with hip fracture (HF) and (2) to evaluate the significance of dementia and residential care as risk factors for HF in the Australian Capital Territory (ACT), Australia.

Methods We performed a prospective study of 555 consecutive patients ( $\geq 60$ years) with HF (mean age 82.6 \pm 7.9 (SD) years; $74.2 \%$ women) within 162,608 person-years of observation. The main predictor variables of HF were, prefracture diagnosed dementia of any type and residential status. ACT population estimates and age- and genderspecific prevalence rates of dementia in the ACT population were used to calculate the relative risk of $\mathrm{HF}$ in demented people.

Results Of those with HF, 176 (31.7\%) were diagnosed with dementia prior to the fracture. Multiple logistic regression analysis revealed that dementia in HF patients was associated with history of stroke $(\mathrm{OR}=2.2 ; 95 \% \mathrm{CI}$ $1.2-4.0 ; p=0.008)$, residential care $(\mathrm{OR}=6.7 ; 95 \%$ CI $4.5-$ $10.2 ; p=0.001)$ and older age $(\mathrm{OR}=1.03 ; 95 \%$ CI $1.0-1.1$; $p=0.036$ ). The overall relative risk (RR) for HF in persons with dementia was 6.3 (95\% CI 5.1-7.1) times higher than in those without pre-fracture dementia, and the RR in the young-old (60-79 years) with dementia was higher than in the old-old ( $\geq 85$ years). The RR of HF for demented persons living in long-term residential care facilities compared to the non-demented age-matched community-
\end{abstract}

A. A. Fisher $\cdot$ M. W. Davis $\cdot$ W. Srikusalanukul $\cdot$ M. M. Budge Department of Geriatric Medicine,

The Canberra Hospital and Australian National University, Canberra, ACT, Australia

A. A. Fisher $(\bowtie)$

Department of Geriatric Medicine, The Canberra Hospital, P.O. Box 11, Woden, ACT 2606, Australia

e-mail: alex.fisher@act.gov.au dwelling population was $16.3(95 \%$ CI $14.4-18.2$; $p=0.001$ ).

Conclusions This study demonstrated a high prevalence of demented people among HF patients and a 6.3-fold risk for HF in older persons with dementia. This risk is almost 2.6 times greater in demented people living in residential care. These data may be useful in health policy decisions and strongly support development of targeted HF prevention strategies, planning and allocation of resources and prioritisation of prevention efforts toward those with dementia, especially in residential care.

Keywords Hip fracture · Dementia · Risk · Prevalence . Long-term care residents

\section{Introduction}

Hip fracture (HF), the most serious complication of osteoporosis and one of the most devastating diseases of older adults, is an important public health problem [1]. The burden of HF due to a high incidence, health impact and cost is expected to increase significantly over coming decades because of rapid population ageing. Identification of the main risk factors for $\mathrm{HF}$ is a prerequisite for developing preventative strategies and allocation of health and welfare resources.

Although in older age the incidence of both HF and dementia increases exponentially, the relationship between these two diseases is not well understood. Dementia and cognitive impairment are regarded as risk factors for HF in some studies [2-5] but are not listed in others [6-9]. It has been reported that patients with dementia are more likely to have HF [10-15]. Dementia is often diagnosed at the time of HF [10,12]. Among patients with Alzheimer's disease, the increased risk of HF has been reported to be 2.1- [16] to 
2.4- [13], to 2.7- [12], to 6.9-fold [17]. However, no significant difference in bone density of women with mild dementia compared with normals was found [18]. In some studies, HF was associated with dementia only in women but not in men [13] whereas others reported a 3.6-fold increased HF in men and a 2.6-fold increase in women with Alzheimer's disease [12]. HFs were increased 12-fold in a psychiatric hospital compared with the general population in men and 7-fold greater in women [19].

We are unaware of published data concerning the community prevalence of pre-HF dementia in older people with HF. In one study of institutionalised people in Canada, persons with HF were two times more likely to have Alzheimer's disease [16]. Thus, although several previous studies involving older adults have shown an increased risk of $\mathrm{HF}$ in demented subjects, the data remain controversial, the effect of residential status is unknown and no systematic study on prevalence of dementia prior to HF has yet been undertaken. Consequently, relevant preventive strategies have not been identified. Therefore, the objectives of our study were (1) to estimate the prevalence of dementia in older people with HF and (2) to evaluate the significance of dementia and residential care as risk factors for HF. We hypothesised that dementia is a prevalent condition in older $\mathrm{HF}$ patients and is an important risk factor for HF, especially in older subjects living in long-term residential facilities.

\section{Materials and methods}

About $1.6 \%$ of the Australian population lives in the ACT. All patients with HFs are referred for specialist surgical assessment and treatment to the Canberra Hospital only. As all patients with HF are treated in one hospital with a centralised, comprehensive, electronic medical record system used by all medical care providers, the ACT is well suited for studies of disease associations. We prospectively collected data on older HF patients from July 2000 to July 2004. All patients were aged 60 years and older and had lowenergy hip fracture. Patients with subtrochanteric fracture or pathological HF related to known primary or metastatic bone cancer, multiple myeloma or Paget's disease were excluded. Pre-fracture dementia (of any type) was diagnosed by local medical officers and/or geriatricians. There was substantial overlap between cases classified as Alzheimer's disease and vascular dementia, with a high frequency of mixed dementia. In this study, subtypes of dementia were not analysed separately. Because HF and perioperative events may unmask or contribute to significant and persistent cognitive impairment, subjects in whom dementia was first diagnosed after hospitalisation and surgery were considered in this analysis as "non-demented". Age- and gender-specific prevalence rates of dementia among patients with $\mathrm{HF}$ in ACT were compared with the rates of dementia in the ACT population [20]. The population of the ACT was calculated using data obtained from the Australian Bureau of Statistics [21]. The population of the ACT from 2001 to 2004 increased from 319,317 to 324,119 , with a mean of 322,078 .

Data are presented as the mean $\pm \mathrm{SD}$. The unpaired $t$ test was used to determine the significance of any difference between HF patients with and without dementia. Group differences of categorical data were tested by chi-square $\left(\chi^{2}\right)$ analysis with Fisher's exact test. Logistic regression analysis was used to assess in HF patients the association between dementia and age, gender, co-morbid conditions, use of walking aids and residential status. $P$ values less than 0.05 were considered statistically significant. All statistical procedures were performed using statistics software Stata version 7, State Press, TX, USA. The ACT Health and Community Care Human Research Ethics Committee approved the study.

\section{Results}

Characteristics of older hip fracture patients and prevalence of dementia

The mean annual incidence of HF in persons aged 60 years and older in the ACT was 341.3 per 100,000 . Of 555 consecutive older persons hospitalised with non-pathological low-impact trauma HF, $176(31.7 \%)$ were diagnosed with dementia prior to the fracture. Dementia was the second most common co-morbid condition after hypertension $(42.2 \%)$. The demographic and clinical characteristics of older patients with HF categorised by pre-fracture diagnosis of dementia are given in Table 1. The HF patients with dementia compared with those without dementia were significantly older, more often had cerebrovascular disease including history of stroke and more often used walking aids. The majority (65.9\%) of demented patients lived in long-term residential care facilities. In both groups, the proportion of women, patients with cervical or trochanteric HF, with hypertension and a history of myocardial infarction, atrial fibrillation, Parkinson's disease or chronic pulmonary obstructive disease as well as smokers (including ex-smokers and current smokers) and alcohol overusers were similar.

All variables associated with pre-fracture dementia from Table 1 were further examined. Multiple logistic regression analysis revealed that in HF, age, history of stroke and institutionalisation were independently and significantly associated with dementia (Table 2). 
Table 1 Demographic and clinical characteristics in older patients with hip fracture (HF) by pre-fracture diagnosed dementia

\begin{tabular}{|c|c|c|c|}
\hline Characteristic & $\begin{array}{l}\text { With dementia } \\
(n=176)\end{array}$ & $\begin{array}{l}\text { Without } \\
\text { dementia } \\
(n=379)\end{array}$ & $\begin{array}{l}P \\
\text { value }\end{array}$ \\
\hline Age (years \pm SD) & $84.5 \pm 6.1$ & $81.7 \pm 8.5$ & 0.001 \\
\hline Women (\%) & 77.8 & 72.6 & 0.111 \\
\hline Cervical HF (\%) & 55.1 & 59.1 & 0.428 \\
\hline $\begin{array}{l}\text { Trochanteric HF } \\
(\%)\end{array}$ & 44.9 & 40.9 & 0.214 \\
\hline Hypertension (\%) & 37.6 & 44.6 & 0.072 \\
\hline $\begin{array}{l}\text { Coronary artery } \\
\text { disease }(\%)\end{array}$ & 30.6 & 20.6 & 0.070 \\
\hline $\begin{array}{l}\text { History of } \\
\text { myocardial infarction } \\
(\%)\end{array}$ & 5.8 & 5.3 & 0.469 \\
\hline $\begin{array}{l}\text { History of stroke } \\
(\%)\end{array}$ & 20.5 & 8.3 & 0.001 \\
\hline $\begin{array}{l}\text { Cerebrovascular } \\
\text { disease }(\%)\end{array}$ & 30.8 & 14.8 & 0.001 \\
\hline $\begin{array}{l}\text { Atrial fibrillation } \\
(\%)\end{array}$ & 14.3 & 13.1 & 0.404 \\
\hline $\begin{array}{l}\text { Parkinson's } \\
\text { disease }(\%)\end{array}$ & 4.7 & 4.7 & 0.575 \\
\hline $\begin{array}{l}\text { Chronic } \\
\text { pulmonary } \\
\text { obstructive disease } \\
(\%)\end{array}$ & 12.6 & 9.0 & 0.120 \\
\hline $\begin{array}{l}\text { History of smoking } \\
(\%)\end{array}$ & 12.2 & 15.0 & 0.452 \\
\hline $\begin{array}{l}\text { Alcohol over-users } \\
(>4 \text { drinks/day) }(\%)\end{array}$ & 3.5 & 7.1 & 0.066 \\
\hline $\begin{array}{l}\text { Use of walking } \\
\text { aids }(\%)\end{array}$ & 43.6 & 29.8 & 0.001 \\
\hline $\begin{array}{l}\text { Institutionalisation } \\
(\%)\end{array}$ & 65.9 & 19.8 & 0.001 \\
\hline
\end{tabular}

Risk of hip fracture in patients with dementia

Table 3 shows the prevalence of dementia in patients with $\mathrm{HF}$ and in the general population in the ACT. Both the prevalence of HFs and dementia increased exponentially with age. While the prevalence of dementia was not affected by gender, the proportion of women with HF after the age of 85 years was significantly higher than the proportion of men with HF $(48.5 \%$ vs. $37.1 \%$; $p=0.023)$. Overall, the RR for HF in older persons with dementia was 6.3 times higher than in those without pre-fracture diagnosed dementia. The highest RRs were observed in the groups aged 60-74 and 75-79 years. In demented persons aged 80-84 and $\geq 85$ years compared with nondemented, the risks of HF were lower (2.2-2.7 and 1.5, respectively) but still highly significant $(p=0.001)$ for women and for both genders combined. RR was not statistically significantly elevated only for men 85 years of age and older. However, $62.9 \%$ of HFs occurred in men before the age of 85 years, and the number may be too small to draw a firm conclusion. In total, the annual rates of HF in older demented persons were $2.76 \%$ for women, $1.23 \%$ for men and $2.15 \%$ for both genders combined while in the groups of non-demented people they were $0.33 \%$, $0.15 \%$ and $0.25 \%$ respectively. Figure 1 demonstrates the rates of HF per 100,000 person-years in four age groups with and without dementia. Total rates increased in the demented population from 366 among 60-74 year olds to 3,510 among subjects 85 years and over and in the nondemented population from 58 to 1,888 , respectively.

Effects of residential status and dementia

About one third (191/555) of all HFs in older persons occurred in people living in long-term residential care facilities. Of $176 \mathrm{HF}$ patients with dementia, two thirds were living in residential care prior to fracture. Table 4 demonstrates RR for HF in older persons with and without dementia living in long-term residential care facilities. For institutionalised older people, the risk of HF was 5.3 times greater than for independently living persons. Residents of long-term-care facilities with dementia compared with the non-demented community-dwelling population had a 16.3fold increase in risk of HF.

\section{Discussion}

This study has four main findings: (1) about one third of all older persons with HF had a pre-fracture diagnosis of dementia; (2) a 6.3-fold increased risk of HF was found for older persons with clinically evident dementia compared with those without; (3) this risk is a further 2.6 times higher for demented people living in long-term residential care facilities; and (4) the young-old (60-79 years) with dementia have a higher RR of HF than the old-old ( $\geq 80$ years) with dementia diagnosed prior to HF admission.

Table 2 Association between dementia and selected socio-demographic and clinical characteristics in older patients with hip fracture: multivariate logistic regression analysis

\begin{tabular}{llll}
\hline Characteristic & Odds ratio & $95 \%$ CI & $P$ value \\
\hline Age & 1.03 & $1.00-1.06$ & 0.036 \\
Male gender & 0.96 & $0.59-1.57$ & 0.864 \\
History of stroke & 2.22 & $1.23-4.00$ & 0.008 \\
Institutionalisation & 6.74 & $4.45-1.21$ & 0.001 \\
\hline
\end{tabular}

All variables listed in Table 1 were analysed; variables that were not significant, except gender, are not shown

CI confidence interval 
Table 3 Prevalence of dementia (D) in patients with hip fracture (HF) and in the general population in Australian Capital Territory (ACT) in 2001-2004

\begin{tabular}{|c|c|c|c|c|c|c|}
\hline \multirow[t]{2}{*}{ Age (years) } & \multicolumn{2}{|c|}{ Patients with HF } & \multicolumn{2}{|c|}{ ACT population } & \multirow[t]{2}{*}{ Relative risk $(95 \% \mathrm{CI})$} & \multirow[t]{2}{*}{$P$ Value } \\
\hline & $\mathrm{D} n(\%)$ & Total & $\mathrm{D} n(\%)$ & Total & & \\
\hline \multicolumn{7}{|l|}{ Men } \\
\hline $60-74$ & $3(10.3)$ & 29 & $260(1.9)$ & 13667 & $5.44(1.3-15.0)$ & 0.009 \\
\hline $75-79$ & $5(25.0)$ & 20 & $155(5.8)$ & 2657 & $4.3(1.6-8.5)$ & 0.002 \\
\hline $80-84$ & $13(31.7)$ & 41 & $185(11.9)$ & 1557 & $2.7(1.6-4.1)$ & 0.001 \\
\hline$\geq 85$ & $18(34.0)$ & 53 & $188(23.2)$ & 812 & $1.5(0.9-2.1)$ & 0.092 \\
\hline Total & $39(27.3)$ & 143 & $788(4.2)$ & 18693 & $6.5(4.8-8.4)$ & 0.001 \\
\hline \multicolumn{7}{|l|}{ Women } \\
\hline $60-74$ & $4(9.5)$ & 42 & $218(1.5)$ & 14269 & $6.2(2.0-15.5)$ & 0.001 \\
\hline $75-79$ & $26(36.6)$ & 71 & $215(6.3)$ & 3397 & $5.8(4.0-7.8)$ & 0.001 \\
\hline $80-84$ & $27(27.3)$ & 99 & $298(12.6)$ & 2356 & $2.2(1.5-3.0)$ & 0.001 \\
\hline$\geq 85$ & $80(40.0)$ & 200 & $510(26.3)$ & 1938 & $1.5(1.3-1.8)$ & 0.001 \\
\hline Total & $137(33.3)$ & 412 & $1240(5.6)$ & 21959 & $5.9(5.1-6.8)$ & 0.001 \\
\hline \multicolumn{7}{|l|}{ Both genders } \\
\hline $60-74$ & $7(9.9)$ & 71 & $478(1.7)$ & 27936 & $5.8(2.6-14.2)$ & 0.001 \\
\hline $75-79$ & $31(28.2)$ & 91 & $370(6.1)$ & 6054 & $5.6(4.0-7.4)$ & 0.001 \\
\hline $80-84$ & $40(28.6)$ & 140 & $483(12.3)$ & 3912 & $2.3(1.7-3.0)$ & 0.001 \\
\hline$\geq 85$ & $98(38.7)$ & 253 & $698(25.4)$ & 2750 & $1.5(1.3-1.8)$ & 0.001 \\
\hline Total & $176(31.7)$ & 555 & $2048(5.0)$ & 40652 & $6.3(5.5-7.1)$ & 0.001 \\
\hline
\end{tabular}

To our knowledge, this is the first community-wide study focusing on the prevalence of and characteristics associated with dementia in older persons with nonpathological HF. In the present prospective study, 31.7\% of 555 consecutive older HF patients were diagnosed with dementia prior to HF. Others have reported pre-fracture dementia or cognitive impairment in $28 \%$ of $\mathrm{HF}$ patients [22]. In HF patients, dementia was the second most common co-morbid condition after hypertension $31.7 \%$ and $42.2 \%$, respectively), and it was significantly and independently associated with history of stroke, living in a long-term health care facility and age. These data are in agreement with the high prevalence of post-stroke dementia [23-25], the well-known relationship between dementia and age and the fact that dementia is the most potent risk factor for institutionalisation [26, 27].

We found that among older ( $\geq 60$ years) persons with HF, one in three had a pre-fracture diagnosis of dementia or had been living in a long-term residential care facility, one in five was demented and institutionalised and one in eight had suffered a stroke. Of HF patients with dementia, two thirds were living in residential care facilities and one third had suffered a stroke. This indicates the need to develop preventive strategies for HF focusing on older people with dementia, especially those living in long-term-care facilities and with cerebrovascular disease.

We found a 6.3-fold increased risk of $\mathrm{HF}$ in older Australians diagnosed with dementia of any type. In our study, dementia was a more important factor for HF than in other reports from USA [12, 17] and Canada [16]. Our risk factor estimates lie toward the upper end of the range of risk-factor estimates found in other studies. However, previous studies included only patients with Alzheimer's disease and have not examined all subtypes of dementia. Pooled data from 11 European populations showed that of all dementia cases, 53.7\% suffered Alzheimer's disease and $15.8 \%$ vascular dementia [28]. The differences may also reflect a more complete case ascertainment of patients with HF. In Australia, all patients with HF are referred to a hospital, and The Canberra Hospital is the only facility for acute orthopaedic assessment and treatment of such patients in an area with a population of about 320,000 . Thus, we are well positioned to develop reliable incidence rates for HFs.

Our data revealed a significant association between HF and dementia for all age groups in both genders combined, and in women, and in men up to 85 years of age. One study found that dementia is associated with HF only in women [13] whereas others reported the opposite, namely, that risk of HF in demented men is higher than in women [12, 19]. The reason for this is unclear.

A recent analysis has shown no significant difference in prevalence rates for dementia (after standardising for age and gender) between different Australian states and territories [20]. It was estimated that in 2005, the number of Australians with dementia would pass the 200,000 mark and reach $1 \%$ of the population. Extrapolating our results nationally, this translates into 4,300 older demented persons at particular risk of HF. In Australia, the prevalence of both HF [29] and dementia [30] is projected to quadruple by 2050 , and this will have a dramatic effect on the healthcare 
Fig. 1 Age-specific incidence rates (per 100,000 person-years) of hip fractures (HF) in the Australian Capital Territory (ACT) population (2000-2004) for those with and without dementia in men (a), women (b) and total (c)
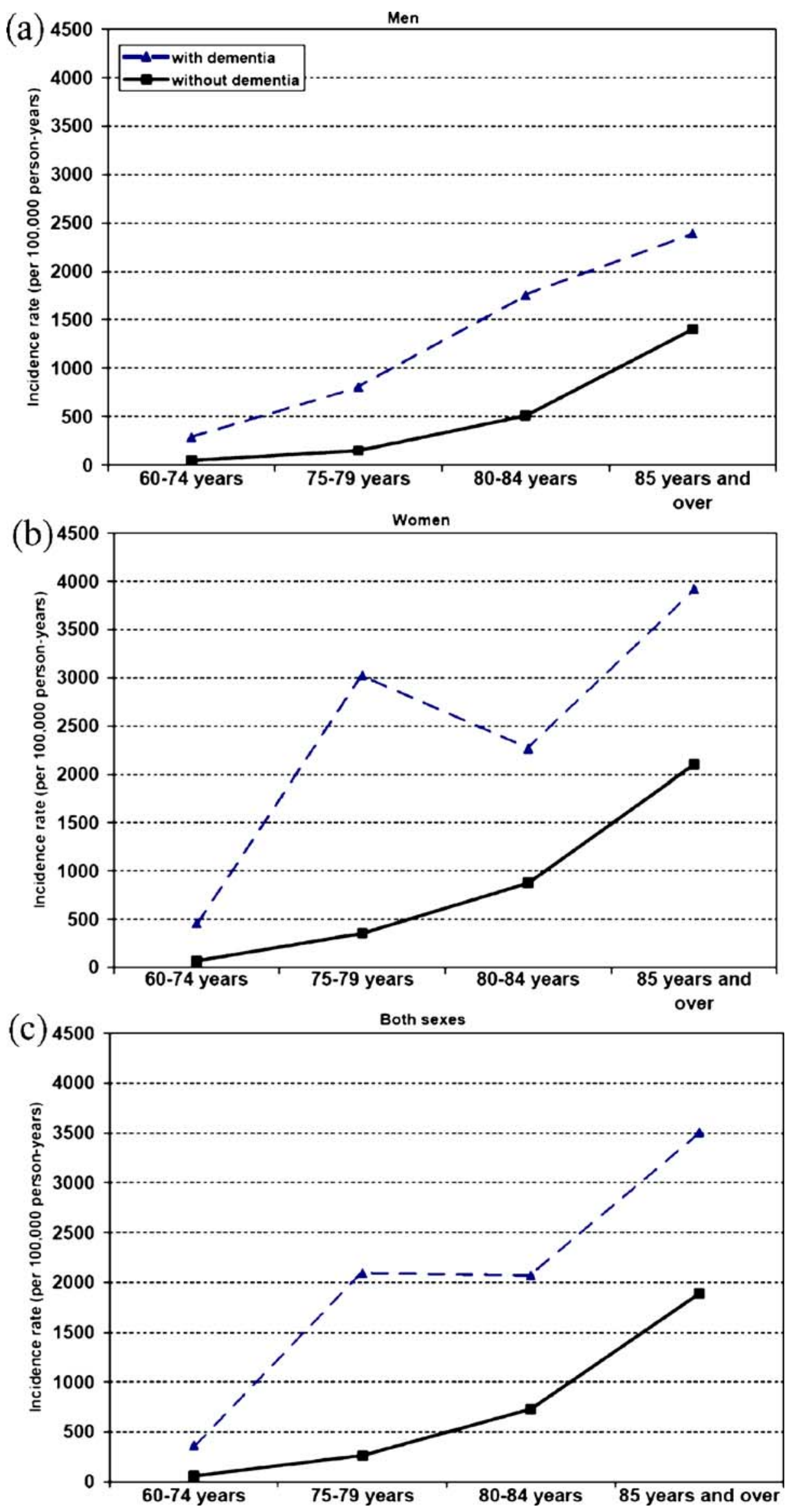
Table 4 The influence of dementia and living in long-term residential care facilities (RCF) on the relative risk of hip fracture (HF) in older adults in the Australian Capital Territory (ACT)

\begin{tabular}{llllllll}
\hline Characteristic & \multicolumn{2}{l}{ Patients with HF } & & \multicolumn{2}{l}{ ACT population $(\geq 60$ years $)$} & & Relative risk (95\% CI) \\
\cline { 2 - 3 } & From RCF $n(\%)$ & Total value & & Institutionalised & Total & \\
\hline People in RCF & $191(34.4 \%)$ & 555 & & $2,070(5.1 \%)$ & 40,652 & $5.3(4.6-6.0)$ & 0.001 \\
People with dementia & $116(65.9 \%)$ & 176 & & $1,603(3.9 \%)$ & $3,8137^{\text {a }}$ & $16.3(14.4-18.2)$ & 0.001 \\
\hline
\end{tabular}

$a$ Total ACT population aged 60 years and over without dementia living at home

system and its resources. With the prolongation of life expectancy, the worldwide projections for these devastating diseases are similar [31, 32]. The expected increase in the number of demented people with HF should prompt targeted prevention strategies, including prevention and treatment of osteoporosis and falls interventions and should include modifiable risk factors for cognitive impairment, especially vascular. There should be a focus on persons diagnosed with dementia (of any type) and people living in long-term residential care.

A recently published study showed an independent relation between HF and Alzheimer's disease and concluded that "mechanisms other than falling and osteoporosis must be involved in HF" [33]. Our observation that dementia is more strongly associated with HF in the young-old age than in the old-old age supports the view that age-related increase in bone frailty is not the only cause of this association. The mechanisms that link dementia and HF are likely to be multiple, as both conditions demonstrate overlapping pathophysiological characteristics (hypovitaminosis $\mathrm{D}$, secondary hyperparathyroidism, dysregulation in calcium homeostasis, weight loss and genetic abnormalities). These require further evaluation. Meanwhile, the most likely explanation for the differing strength of association of dementia with HF across older ages is that in the old-old, factors other than those related to dementia cumulatively contribute to explain much of the variance at that later age. Consequently, the relative influence of dementia at ages between 60 and 80 years may appear to be much greater.

Finally, we found that residents in long-term-care facilities compared with the community-dwelling population have a HF risk of 5.3. In previous reports, the risk of HF in older institutionalised people varied between 3.3 [34] and 5.8-7.6 [35]. However, our study also showed that in older persons with dementia living in residential care, the RR of HF compared with non-demented older adults living in the community reached 16.3 , which is 2.6 times higher than in the total demented population and three times higher than in institutionalised people without dementia. Residents with dementia fall approximately two times more often than their counterparts without dementia [36].
Therefore, people living in long-term-care residential facilities, especially those with dementia, should be a clear target in HF preventive strategies.

Some limitations of this study should be mentioned. The diagnosis of dementia by different doctors is of potential concern. However, our analysis of dementia in patients with and without HF rely on the diagnosis by the same group of family doctors and specialists, and HF patients were categorised on diagnoses of dementia prior to the HF; therefore, it is unlikely that ascertainment would systematically differ between HF patients and the total population. Importantly, in all HF patients presenting with dementia, the diagnosis was confirmed by the consulting geriatrician in the hospital. The estimates of the prevalence of dementia in HF patients discharged after fracture repair were higher, but these data were not included in the present analysis. If the total (pre- and post-HF) number of demented patients with HF were considered, the association between dementia and HF would be even stronger. The generalisability of our findings to other populations is limited, as only a few nonwhite older adults were represented in our study.

In summary, our study demonstrates a high prevalence of dementia among HF patients and a 6.3-fold risk for HF in older persons with dementia, with a further 2.6 increase of this risk in demented people living in institutions. These data may be useful in health policy decisions and should prompt targeting of HF prevention strategies, planning and allocation of resources and prioritising prevention and research efforts.

Acknowledgements Author contributions: Alexander Fisher did the study concept and design, acquisition of subjects and data, analysis and interpretation of data and preparation of manuscript. Michael Davis did the study concept and design and preparation of manuscript. Wichat Srikusalanukul and Marc Budge were involved in analysis and interpretation of data and preparation of manuscript.

Disclaimers: Financial disclosure: No authors of this paper have financial support for research, consultantships or speakers forum or any company stocks or patents.

Sponsor's role: None 


\section{References}

1. Johnell O, Kanis JA (2004) An estimate of the worldwide prevalence, mortality and disability associated with hip fracture. Osteoporos Int 15:897-902

2. Boonen S, Broos P, Haentjens P (1999) Factors associated with hip fracture occurrence in old age. Implications in the postsurgical management. Acta Chir Belg 99:185-189

3. Kanis J, Johnell O, Gullberg B et al (1999) Risk factors for hip fracture in men from southern Europe: the MEDOS study. Mediterranean Osteoporosis Study. Osteoporos Int 9:45-54

4. van Staa TP, Leufkens HG, Cooper C (2002) Utility of medical and drug history in fracture risk prediction among men and women. Bone 31:508-514

5. Taylor BC, Schreiner PJ, Stone KL et al (2004) Long-term prediction of incident hip fracture risk in elderly white women: study of osteoporotic fractures. J Am Geriatr Soc 52:1479-1486

6. Lauritzen JB (1996) Hip fractures: incidence, risk factors, energy absorption, and prevention. Bone 18:65S-75S

7. Young Y, Myers AH, Provenzano G (2001) Factors associated with time to first hip fracture. J Aging Health 13:511-526

8. Nguyen ND, Pongchaiyakul C, Center JR et al (2005) Identification of high-risk individuals for hip fracture: a 14-year prospective study. J Bone Miner Res 20:1921-1928

9. Yoshimura N, Suzuki T, Hosoi T et al (2005) Epidemiology of hip fracture in Japan: incidence and risk factors. J Bone Miner Metab 23(Suppl): $78-80$

10. Birge SJ, Morrow-Howell N, Proctor EK (1994) Hip fracture. Clin Geriatr Med 10:589-609

11. Gorelick PB, Freels S, Harris Y et al (1994) Epidemiology of vascular and Alzheimer' dementia among African Americans in Chicago, IL: baseline frequency and comparison of risk factors. Neurology 44:1391-1396

12. Melton LJ 3rd, Beard CM, Kokmen E et al (1994) Fracture risk in patients with Alzheimer's disease. J Am Geriatr Soc 42:614-619

13. Johansson C, Skoog I (1996) A population-based study on the association between dementia and hip fractures in 85-year olds. Aging (Milano) 8:189-196

14. Guo Z, Wills P, Viitanen M et al (1998) Cognitive impairment, drug use, and the risk of hip fracture in persons over 75 years old: a community-based prospective study. Am J Epidemiol 148:887-892

15. Sato Y, Kanoko T, Satoh K et al (2004) Risk factors for hip fracture among elderly patients with Alzheimer's disease. J Neurol Sci 223:107-112

16. Weller II (2000) The relation between hip fracture and alzheimer's disease in the canadian national population health survey health institutions data, 1994-1995. A cross-sectional study. Ann Epidemiol 10:461

17. Buchner DM, Larson EB (1987) Falls and fractures in patients with Alzheimer-type dementia. Jama 257:1492-1495

18. Kipen E, Helme RD, Wark JD et al (1995) Bone density, vitamin $\mathrm{D}$ nutrition, and parathyroid hormone levels in women with dementia. J Am Geriatr Soc 43:1088-1091
19. Hansson LI, Ceder L, Svensson K et al (1982) Incidence of fractures on the distal radius and proximal femur: comparison of patients in a mental hospital and the general population. Acta Orthop Scand 53:721-726

20. Access Economics (2005) Dementia estimates and projections: Australian States and Territories, Report for Alzhemer's Australia. In, Canberra

21. ABS Australian Bureau of Statistics. Population by age and sex. In: Cat No 3201.0, 2001-2005. Canberra

22. Gruber-Baldini AL, Zimmerman S et al (2003) Cognitive impairment in hip fracture patients: timing of detection and longitudinal follow-up. J Am Geriatr Soc 51:1227-1236

23. Gorelick PB (2005) William M. Feinberg lecture: cognitive vitality and the role of stroke and cardiovascular disease risk factors. Stroke 36:875-879

24. Leys D, Henon H, Mackowiak-Cordoliani MA et al (2005) Poststroke dementia. Lancet Neurol 4:752-759

25. Mackowiak-Cordoliani MA, Bombois S, Memin A et al (2005) Poststroke dementia in the elderly. Drugs Aging 22:483-493

26. Banaszak-Holl J, Fendrick AM et al (2004) Predicting nursing home admission: estimates from a 7-year follow-up of a nationally representative sample of older Americans. Alzheimer Dis Assoc Disord 18:83-89

27. Bharucha AJ, Pandav R, Shen C et al (2004) Predictors of nursing facility admission: a 12-year epidemiological study in the United States. J Am Geriatr Soc 52:434-439

28. Lobo A, Launer LJ, Fratiglioni L et al (2000) Prevalence of dementia and major subtypes in Europe: A collaborative study of population-based cohorts. Neurologic Diseases in the Elderly Research Group. Neurology 54:S4-S9

29. Sanders KM, Seeman E, Ugoni AM et al (1999) Age- and genderspecific rate of fractures in Australia: a population-based study. Osteoporos Int 10:240-247

30. Jorm AF, Dear KB, Burgess NM (2005) Projections of future numbers of dementia cases in Australia with and without prevention. Aust N Z J Psychiatry 39:959-963

31. Gullberg B, Johnell O, Kanis JA (1997) World-wide projections for hip fracture. Osteoporos Int 7:407-413

32. Ferri CP, Prince M, Brayne C et al (2005) Global prevalence of dementia: a Delphi consensus study. Lancet 366:2112-2117

33. Weller I, Schatzker J (2004) Hip fractures and Alzheimer's disease in elderly institutionalized Canadians. Ann Epidemiol 14:319-324

34. Brennan nee Saunders J, Johansen A, Butler J, Stone M et al (2003) Place of residence and risk of fracture in older people: a population-based study of over 65-year-olds in Cardiff. Osteoporos Int 14:515-519

35. Ooms ME, Vlasman P, Lips P et al (1994) The incidence of hip fractures in independent and institutionalized elderly people. Osteoporos Int 4:6-10

36. van Doorn C, Gruber-Baldini AL, Zimmerman S et al (2003) Dementia as a risk factor for falls and fall injuries among nursing home residents. J Am Geriatr Soc 51:1213-1218 